\title{
Recurrent Hydatidiform Mole: A Case Report of Five Consecutive Molar Pregnancies Complicated by Thyrotoxicosis and Review of Literature
}

\author{
SABERA KHATUN
}

\begin{abstract}
:
Hydatidiform mole (HM) is the most common form of Gestational Trophoblastic Disease (GTD). Recurrence of HM is extremely rare. Here we report the case report of a patient with five consecutive complete hydatidiform moles without any normal pregnancy.

A 41-years old lady, was referred to Bangabandhu Sheikh Mujib Medical University (BSMMU), Dhaka, Bangladesh with H/O repeated molar pregnancies. Her first molar pregnancy was in 2005, second in 2006, third in 2007 \& fourth in 2014. All the molar pregnancies were managed by suction evacuation at her base hospital. Following evacuation of $4^{\text {th }}$ molar pregnancy at base hospital, she was referred to BSMMU for subsequent management. Regular follow-up was done using molar card. All the pregnancies were complete hydatidiform mole (CHM) and were confirmed clinically and sonographically. None of the molar pregnancies needed treatment with chemotherapy.

During her fifth molar pregnancy she developed shortness of breath and palpitation. Diagnostic work up in our hospital confirmed complete molar pregnancy with thyrotoxicosis, for which she received b-blocker agent and after normalization of thyrotoxicosis, she underwent total abdominal hysterectomy on 11. 10. 18. Now she is on regular follow up by serum bhCG and has no complication.
\end{abstract}

Key words: Hydatidiform Mole, Recurrent Mole, Thyrotoxicosis

\section{Introduction:}

Hydatidiform mole is the commonest form of Gestational Trophoblastic Disease (GTD). These are characterized by hydropic swelling of the placental trophoblastic villi, atypical hyperplasia of trophoblasts and absent or abnormal fetal development. It occurs in 1 in 600 pregnancies in the UK population ${ }^{1}$. However, this increases 10 -fold for women who have already experienced a molar pregnancy. A 10 year survey of over 5000 subsequent pregnancy outcomes following a molar pregnancy found that outcomes were similar to the normal population except that the risk of a subsequent HM which occurred in 1 in 68 pregnancies ${ }^{1}$. This observation supports previous reports that the risk of an $\mathrm{HM}$ in a subsequent pregnancy increases to $1-2 \%$ following a molar pregnancy and may be as high as $23 \%$ for women with two consecutive molar pregnancies ${ }^{2}$.
Subsequent pregnancy outcomes for women with three or more molar pregnancies have not been systematically reported.

Molar pregnancies are of two major types, Complete Hydatidiform Mole (CHM) and Partial Hydatidiform Mole (PHM). Where recurrent molar pregnancies have been defined as complete mole or partial mole the second molar pregnancy may be of either type but more usually of the same type as the index previous mole ${ }^{2}$. However for women with two or more molar pregnancies, subsequent molar pregnancies are more likely to be CM. CHM is associated with a significant increased risk of developing Gestational Trophoblastic Neoplasia (GTN) than PHM. The rate of developing GTN from CM and PM are $15 \%$ and $1 \%$ repectively ${ }^{1}$. Whether this risk increases in subsequent molar pregnancies it remains 
controversial. Although recurrent molar pregnancies are a rare occurrence, it is clear that women who have had a previous mole have a higher risk of recurrence than the general population ${ }^{3}$.

\section{Case report:}

A 40 years old woman reported to us on 29.9.2018 with the complain of amenorrhoea for 2 months. She came from a district town of Dhaka Division with reports of transabdominal ultrasonography done on 23.9.18 and repeated on 26.9.18. Both reports showed molar pregnancy. Her serum b-hCG done on 23.9.18 and it was 2,25,000 $\mathrm{miu} / \mathrm{ml}$. Her x-ray chest, CBC, fasting and 2 hours after breakfast blood sugar level, serum electrolytes, SGPT, creatinine level and serum albumin were within normal limit. Her cardiac status was normal.

As a mandatory test for evaluation of thyroid status, she had serum TSH and FT4 level measurement on 3.10.18. TSH level was .02 nmol/L (N-.55-4.78 nmol/ L) and FT4 level was 359.1pmol/L. (N-58.1-140.6 $\mathrm{pmol} / \mathrm{L})$.

Regarding obstetric history, she is married for 20 years but no normal pregnancy. Unfortunately she became pregnant for 4 times. But all the pregnancies were molar pregnancy and each time she had suction evacuation for molar pregnancy. This was her $5^{\text {th }}$ pregnancy and it was also molar pregnancy. Her first molar pregnancy was in 2005 , second in 2006 , third in 2007, fourth in 2014 and this was her fifth pregnancy in 2018.

Four years after her $4^{\text {th }}$ pregnancy, she consulted with us for pre-conception counseling regarding her subsequent pregnancy fate. It was not possible to perform genotyping \& we advised her to take a chance. She consulted us during her $5^{\text {th }}$ pregnancy and unfortunately it was again CHM, confirmed clinically and sonographically. She wanted to remove the uterus. The current pregnancy was complicated by Thyrotoxicosis and managed conservatively by $\beta$ blockers. She underwent total abdominal hysterectomy (TAH) and left sided salpingooophorectomy and right sided salpingectomy with mole in situ (Fig. 1).

On cut section of the uterus, endometrial cavity was found distorted by vescicular grape like structures. Total volume of the vescicular structure was 100.c.c. Size of the biggest vescicle was $2 \mathrm{~cm}$. (Fig. 2)

Histopathological report showed complete hydatidiform mole. Forty eight hours after hysterectomy serum b-hCG sharply fell down to $1,63,541.70 \mathrm{miu} / \mathrm{ml}$. She was advised to do weekly b-hCG. But she was reluctant to do so, ultimately she had serum b-hCG on 31.10.18 and it was $267.90 \mathrm{miu} / \mathrm{ml}$. Her thyroid status become normal after hysterectomy and on 16.10.18 serum FT4, FT3 and TSH level was $27.93 \mathrm{pmol} / \mathrm{L}, 8.10 \mathrm{pmol} / \mathrm{L}$ and 0.03 pmole/L respectively.

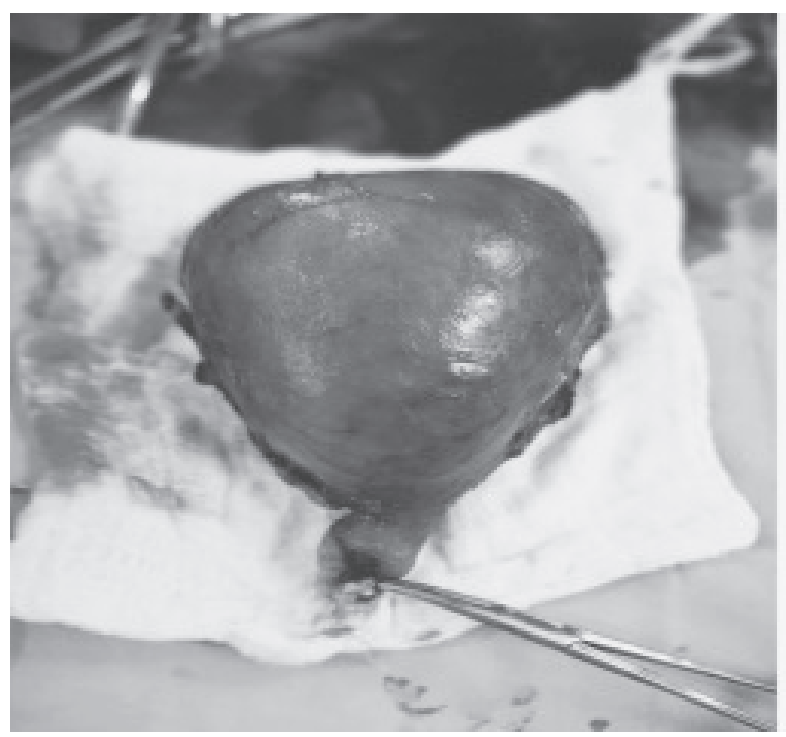

Fig.-1

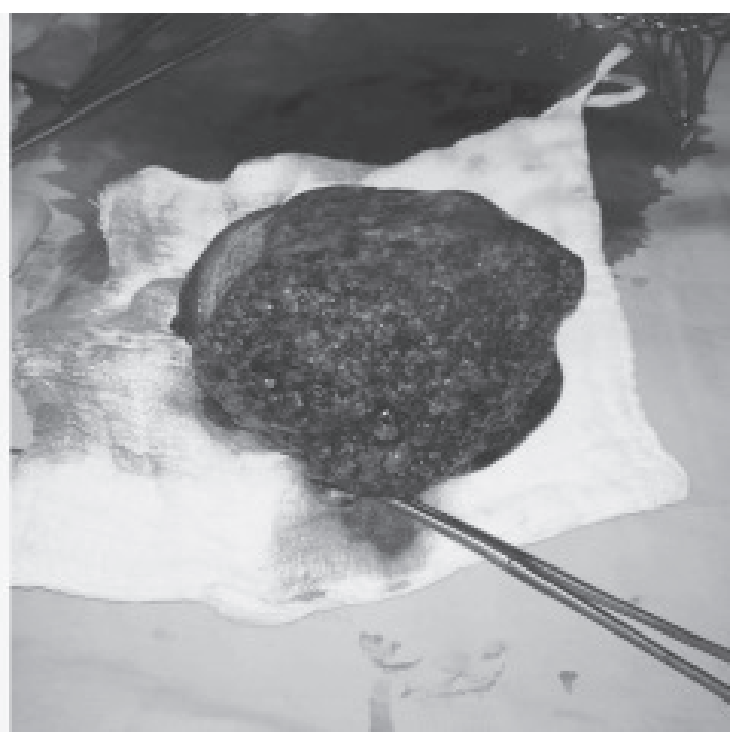

Fig.-2 


\section{Discussion:}

The incidence of molar pregnancy in South Asian region is higher than rest of the world. The cause of molar pregnancy is unclear and also it is not clear, why the incidence is higher in South Asian rice eater zone. There are some risk factors. It occurs at the extremes of the reproductive years. For women over 40 years of age, the chance of molar pregnancy is 10 times higher than general population. On the other hand it is 1.3 fold raised in teenagers ${ }^{4}$. Other risk factors are dietary habit, gravidity, and use of contraceptive ${ }^{(5,6)}$

According to Steigard SJ in 2003, the incidence of recurrent molar pregnancies ranges from 5 to 40 fold increased than general population ${ }^{5}$ A report from the United Kingdom says that women having two molar pregnancies, the chance of having third molar pregnancy is 1 in 6.5 pregnancies $^{3}$. This risk diminishes if there is a normal pregnancy following HM.

It is now recognized that recurrent $\mathrm{HM}$ run in families. Recently this has been evaluated. The condition is called Familial Recurrent Hydatidiform Mole (FRHM). FRHM are considered exceedingly rare, with only 21 families reported in the medical literature. It is a rare autosomal recessive condition, most of which are complete mole and the affected women are prone to have higher number of pregnancy losses than the normal population ${ }^{6}$ The reported patient had no known family history of recurrent HM. Genetic studies of the molar tissue suggests mutations in the NLRP7 and KHDC3L genes, have been shown to be responsible for $75 \%$ and $5 \%$ of cases of $\mathrm{FRHM}$ respectively. The gene NLRP7 is also known as NALP7 gene, which is located on chromosome $19_{\mathrm{q}}$ 13.3-q13.4 a maternal gene, as a cause of familial biparental $\mathrm{HM}$, and possibly responsible for recurrent spontaneous abortion, stillbirths and intrauterine growth retardation ${ }^{7}$. Genotyping of the complete mole (CM) can be done by which the women prone to be affected by FRHM can be identified. Sporadic complete moles are androgenic while those affected with FRHM are diploid but biparental in origin. We did not do genotyping of our patient as there is no facility for doing that.

\section{Hyperthyroidism:}

Clinically evident hyperthyroidism are found in only $7 \%$ of cases. There may be asymptomatic hyperthyroidism but may present with tachycardia, warm skin, and tremor. Diagnosis can be confirmed by detection of serum free thyroxin $\left(\mathrm{FT}_{4}\right)$ level and triiodothyronine $\left(T_{3}\right)$ level. When hyperthyroidism is suspected, it is important to administer b-adrenergic blocking agents before the induction of anesthesia for molar evacuation, because anesthesia or surgery may precipitate a thyroid storm. The latter may be manifested by hyperthermia, delirium, convulsions, atrial fibrillation, high-output heart failure, or cardiovascular collapse. Administration of $b-$ adrenergic blocking agents prevents or rapidly reverses many of the metabolic and cardiovascular complications of a thyroid storm. Some investigators speculated about the separate chorionic thyrotrophin, but this substance has not been separated.

This patient developed hyper-thyroidism, her THS level was $.02 \mathrm{nmol} / \mathrm{L}$. (normal .55-4.78 nmole/L) . Her FT4 level was highly raised (359.1 pmole/L) from normal level (58.1- 146.6 pmole /L). Preoperatively she was managed by $ß$ blocker agent. Her thyroid status became normal 1 week after total hysterectomy.

Follow up of patients with HM by measuring serial ßhCG levels is very crucial for early detection of Persistent Gestational Trophoblastic Neoplasia (PGTN) which has high potential to malignant change. This patient had first post-hysterectomy ßhCG on 13.10.18, that is 48 hours after hysterectomy. The level sharply reduced to $1,63,541.70 \mathrm{miu} / \mathrm{ml}$ from $2,25,000 \mathrm{miu} / \mathrm{ml}$ preoperatively. She was advised for weekly serum ß-hCG but she had only one B-hCG on 31.10 .18 and it was $267.90 \mathrm{miu} / \mathrm{ml}$. After that she had 2 weekly ß-hCG. It was only 6.4 in March 2019 and 6 in June 2019. Now she will have monthly ßhCG for 2 years. Any deviation from normal value will be treated by chemotherapy. As every molar pregnancy increases the chance of GTN, she needs follow up for 2 years even if she is not a case of GTN.

In conclusion, doctors attending molar pregnancies should be aware of the potential malignant transformation and the genetic predisposition- for early detection, proper referral in time, counseling and early treatment of any PGTN, invasive mole and choriocarcinoma. Doctors should also be aware of Familial Recurrent Hydatidiform Mole. 


\section{Acknowledgement:}

The author would like to thank professor Fariduddin Endocrinologist of BSMMU for his support in the management of this patient.

\section{Reference :}

1. Savage PM, Sita-Lumsden A, Dickson S, lyer R, Everard J, Coleman R, Fisher RA, Short D, Casalboni S, Catalano K et al. The relationship of maternal age to molar pregnancy incidence, risks for chemotherapy and subsequent pregnancy outcome. J Obstet Gynaecol 2013;33:406-411.

2. Sebire NJ, Fisher RA, Foskett M, Rees H, Seckl MJ, Newlands ES. Risk of recurrent hydatidiform mole and subsequent pregnancy outcome following complete or partial hydatidiform molar pregnancy. BJOG 2003;

3. AIMulhim AA. Hydatiform mole. JFCM. 2000;7:57-61. [PMC free article] [PubMed] [Google Scholar].
4. Sebire NJ, Foskett RA, Fisher RA, Rees H, Seckl M, Newlands E. Risk of partial and complete hydatidiform molar pregnancy in relationship to age. BJOG. 2002;109:99102. [PubMed] [Google Scholar]

5. Steigrad SJ. Epidemiology of gestational trophoblastic diseases. Best Pract Res Clin Obstet Gynaecol. 2003;17:837-47. [PubMed] [Google Scholar]

6. Pour Reza M, Agheli N, Baghefi SB. Serum creatinine and urea and protein level changes in hydatidiform mole. JAMA. 1974;230:5801. [PubMed] [Google Scholar]

7. Moglabey YB, Kircheisen R, Seoud M, EI Mogharbel N, Van den Veyver I, Slim R. Genetic mapping of a maternal locus responsible for familial hydatidiform moles. Hum Mol Genet. 1999;8:667-71. [PubMed] [Google Scholar] 